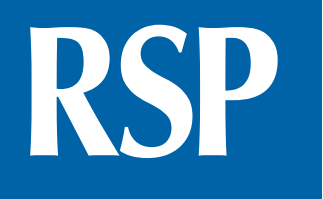

http://www.rsp.fsp.usp.br/
Revista de Saúde Pública

\title{
Frequency and factors associated with falls in adults aged 55 years or more
}

Sabrina Canhada Ferrari Prato', Selma Maffei de Andrade", Marcos Aparecido Sarria Cabrera'", Renata Maciulis Dip"I', Hellen Geremias dos Santos ${ }^{\prime v}$, Mara Solange Gomes Dellaroza Arthur Eumann Mesas"

I Secretaria Municipal de Saúde. Prefeitura do Município de Cambé. Cambé, PR, Brasil

" Departamento de Saúde Coletiva. Centro de Ciências da Saúde. Universidade Estadual de Londrina. Londrina, PR, Brasil

III Departamento de Clínica Médica. Centro de Ciências da Saúde. Universidade Estadual de Londrina. Londrina, PR, Brasil

Iv Programa de Pós-Graduação em Epidemiologia. Faculdade de Saúde Pública. Universidade de São Paulo. São Paulo, SP, Brasil

$\checkmark$ Departamento de Enfermagem. Centro de Ciências da Saúde. Universidade Estadual de Londrina. Londrina, PR, Brasil

\section{ABSTRACT}

OBJECTIVE: The objective of this study is to analyze the frequency and factors associated with falls in adults aged 55 years or more.

METHODS: This is a study inserted into another population-based study with representative sample of persons aged 40 years or more of the urban area in a medium-sized municipality of the State of Paraná, Brazil, in 2011. That study obtained demographic and socioeconomic data and characteristics related to life habits, health conditions, and functional capacity $(n=1,180)$. In 2012, we selected all persons aged 55 years or more $(n=501)$. We have estimated grip strength and the occurrence of a fall since the last interview in $80.6 \%$ of the adults. The crude and adjusted odds ratios (OR) have been calculated by logistic regression according to a hierarchical model.

RESULTS: The rate of fall was $24.3 \%$. After adjustments, we could observe higher chances of falls among women ( $\mathrm{OR}=3.10 ; 95 \% \mathrm{CI} 1.79-5.38)$, among persons aged 65 years or more

Correspondence:

Sabrina Canhada Ferrari Prato

Av. Canadá, 1188

86181-070 Cambé, PR, Brasil

E-mail: sabrinacferrari@yahoo.com.br

Received: 22 Feb 2014

Approved: 19 Jul 2016

How to cite: Prato SCF, Andrade SM, Cabrera MAS, Dip RM, Santos HG, Dellaroza MSG, et al. Frequency and factors associated with falls in adults aged 55 years or more. Rev Saude Publica.

2017;51:37

Copyright: This is an open-access article distributed under the terms of the Creative Commons Attribution License, which permits unrestricted use, distribution, and reproduction in any medium, provided that the original author and source are credited. $(\mathrm{OR}=2.39$; 95\%CI 1.45-3.95), with poor sleep quality $(\mathrm{OR}=1.78$; 95\%CI 1.08-2.93), and with low grip strength $(\mathrm{OR}=2.31 ; 95 \% \mathrm{CI} 1.34-3.97)$.

CONCLUSIONS: Poor sleep quality and low muscle strength can be indicators of increased risk of falls and need assessments and interventions aimed at preventing them.

DESCRIPTORS: Middle Aged. Aged. Accidental Falls. Risk Factors. Health Surveys. 


\section{INTRODUCTION}

The occurrence of falls is related to a complex interaction of risk factors aggravated with aging. A literature review on the subject ${ }^{2}$ points as main risk factors: being female, age, polypharmacy, use of psychotropic substances, previous history of falls, visual impairment, cognitive decline, and environmental factors, such as slippery floors and poorly positioned furniture and carpets. In addition, some conditions or chronic degenerative diseases are associated with higher incidence of falls, such as obesity ${ }^{26}$, hypertension ${ }^{2}$, diabetes ${ }^{28}$, neoplasms ${ }^{24}$, neuropsychiatric diseases ${ }^{2,28}$, and osteomuscular diseases ${ }^{26}$. On the other hand, the regular practice of physical activity stands out as a protective factor ${ }^{20}$.

Disability and serious injuries are among the main consequences of a fall. They imply high economic and social costs, especially when there is impairment of the independence of the individual and the need for specialized care at home or in long-term institutions ${ }^{2}$.

Although there are several studies on falls in the elderly in the community, we can observe a concentration of studies among elderly persons with morbidities, weakened, and institutionalized ${ }^{5}$. The Diretrizes de Prevenção de Quedas em Idosos ${ }^{12}$ (Guidelines for Prevention of Falls in the Elderly - 2010) demonstrate the importance of early identification of older adults at risk. In this context, the objective of this study is to analyze the frequency and factors associated with falls in individuals aged 55 years or more. The knowledge on this profile can direct the efforts of primary care professionals in preventing falls and maintaining functional independence.

\section{METHODS}

This study is part of a larger population-based study (Doenças Cardiovasculares no Estado do Paraná: mortalidade, perfil de risco, terapia medicamentosa e complicações - VIGICARDIO ${ }^{23}$, with representative sample of residents aged 40 years or more in the urban area of Cambé, State of Paraná, Brazil. The municipality has a population of 96,735 inhabitants, according to the 2010 Census $^{\mathrm{a}}$. The calculation of the sample of the study VIGICARDIO considered a margin of error of $3.0 \%, 95 \%$ confidence interval, prevalence of outcome of $50.0 \%$, and increase for losses and refusals of $25.0 \%$, resulting in 1,322 persons to be interviewed. The eighty-six census tracts of the urban area of Cambé were selected and the number of persons to be interviewed in each tract was defined according to the proportional distribution of residents by gender and age group ( for every five years). After drawing the initial block, we draw the corner of the block in which we would initiate the route, counterclockwise, with a sampling interval of 1.2, in order to ensure the representation of all census tracts. Details of the sampling calculation and the process of selection of interviewees can be found in another publication ${ }^{23}$.

The data were obtained using home interviews. We obtained information on life habits, health conditions, use of drugs (with the presence of inserts, prescriptions, or packages), activities of daily living (ADL), and instrumental activities of daily living (IADL), using the scales of Katz et al..$^{10}$ and Lawton and Brody ${ }^{13}$, respectively, and also sleep quality using the Pittsburgh index (PSQI) ${ }^{4}$. Weight and height were verified using a portable electronic scale and an inextensible measuring tape, respectively. We obtained three blood pressure measurements and considered the arithmetic average of the second and third measurements to define hypertension ( $\geq 140 \mathrm{mmHg}$ for systolic blood pressure and/or $\geq 90 \mathrm{mmHg}$ for diastolic blood pressure and/or use of antihypertensive medication $)^{23}$.

The VIGICARDIO data collection took place between February and June 2011, amounting to 1,180 participants. For logistical reasons, individuals aged 55 years or more were selected for this study, corresponding to 501 participants. Between April and August 2012, we conducted

a Instituto Brasileiro de Geografia e Estatística. Censo demográfico 2010: Paraná [cited 2011 May 10]. Available from: http://www. ibge.gov.br/home/estatistica/ populacao/censo2010/tabelas pdff/ total_populacao_parana.pdf a second home interview. Among those participants aged 55 years or more in the first study, $404(80.6 \%)$ were located in the second survey. The losses occurred because of change of address $(n=51)$, hospitalization $(n=3)$, death $(n=11)$, refusal $(n=12)$, or they could not be located after three attempts $(n=20)$. The average time elapsed between the two data surveys 
was fourteen months (minimum of eleven and maximum of eighteen months). There was no significant difference between interviewees and losses regarding age, race, marital status, educational level, economic class, or presence of chronic diseases. Only gender showed significant difference $(\mathrm{p}=0.02)$, with greater loss of men.

The dependent variable corresponded to self-reported accidental fall after the first home interview. The question used was: "Since the last interview, have you fallen?"

The following variables were obtained in the first home interview:

- Demographic and socioeconomic characteristics: gender, age, marital status, race, education, and economic class.

- Characteristics related to life habits and health conditions: leisure-time physical activity, smoking, body mass index, use of psychotropic drugs, sleep quality, report of medical diagnosis for the following morbidities: congestive heart failure (CHF), diabetes mellitus (DM), depression, chronic obstructive pulmonary disease (COPD), neoplasm, and hypertension.

- Characteristics related to functional capacity: visual and/or hearing impairment (self-reported), difficulty to go up or down the stairs, and difficulty to perform activities of daily living $(\mathrm{ADL})^{10}$ and instrumental activities of daily living (IADL) $)^{13}$.

In the second interview, we verified grip strength using a hydraulic hand dynamometer, model SAEHAN SH5001, following the standards recommended by the American Society of Hand Therapists?

For the bivariate and multiple analyses, age was grouped into 55 to 64 years and 65 years or more, race was grouped into white or yellow and black/brown/indigenous, and marital status was grouped into with and without a partner.

Schooling was classified by years of study (zero to three, four to seven, and eight years or more). Economic class was assessed according to the criteria of the Associação Brasileira

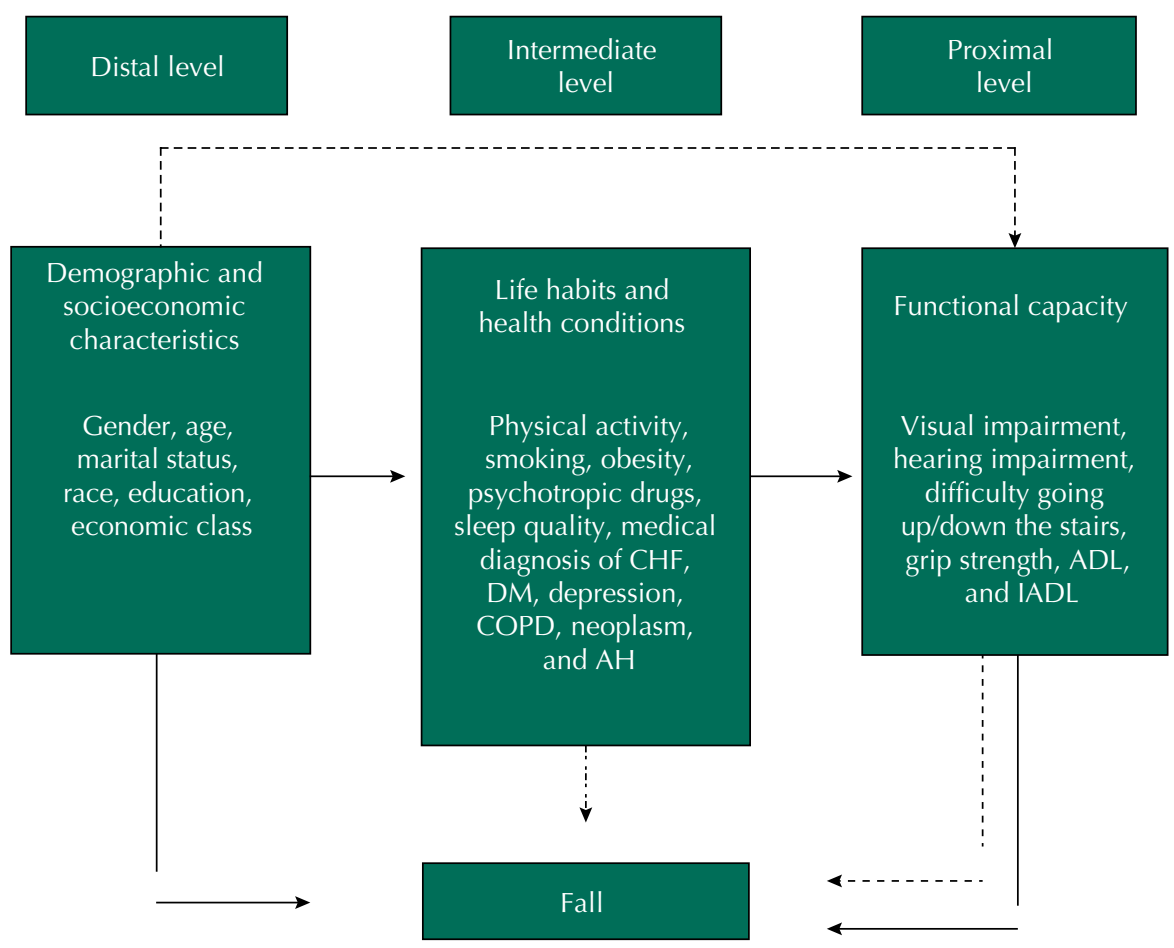

BMI: body mass index; CHF: congestive heart failure; DM: diabetes mellitus; COPD: chronic obstructive pulmonary disease; AH: arterial hypertension; ADL: activities of daily living; IADL: instrumental activities of daily living

Figure. Hierarchical conceptual model of the factors associated with a fall in persons aged 55 years or more. Cambé, State of Paraná, Southern Brazil, 2011 to 2012. 
de Empresas de Pesquisas (ABEP - Brazilian Association of Research Companies) $)^{b}$, grouped into class $\mathrm{A} / \mathrm{B}, \mathrm{C}$, and $\mathrm{D} / \mathrm{E}$.

The recommendations of Haskel et al. ${ }^{8}$ were followed for the assessment of leisure-time physical activity. We considered as practitioners of physical activity those who reported to perform moderate-intensity physical activity (e.g., walking in fast pace, dancing) at least for 30 minutes, five or more times a week, and/or vigorous-intensity physical activity (e.g., running, playing soccer) at least for 20 minutes, three or more times a week. The ones that did not fit these criteria were considered as non-practitioners.

Visual impairment was divided into two categories: individuals without impairment or those who had some visual disorder that did not harm them in carrying out the activities of daily life, and individuals with exacerbated visual impairment (who only saw the outline of objects and needed to be guided on activities of daily living) or those who did not see.

We considered as dependent the persons who reported difficulty in performing two or more activities of daily living or two or more instrumental activities of daily living ${ }^{11}$.

The information related to the continuous use of drugs was collected using supporting elements (inserts, packages, bottles, boxes, or prescriptions) and questions related to the indication, location of where the drug was bought, and use of the drug. We used the Anatomical Therapeutic Chemical classification (N03-N07) ${ }^{\mathrm{c}}$ for the identification of psychotropic drugs.

Sleep habits in the 30 days leading up to the first home interview were assessed using the Pittsburgh sleep quality index (PSQI) ${ }^{4}$. Values greater than five points were considered indicative of poor quality of sleep.

Grip strength was analyzed according to percentiles, separately for men and women. Because there is no cutoff point validated in the literature to define low muscle strength, persons were classified into: $\leq 25$ th percentile (low muscle strength) or $>25$ th percentile.

A portable electronic scale, Plenna brand, was used to measure weight, with a precision of 100 grams. Height was measured using an inelastic and inextensible measuring tape fixed at a wall without baseboard or door. We calculated the body mass index (BMI) for classification of obesity, according to the criteria of the World Health Organization (BMI $<30=$ no, $\geq 30=$ yes $^{21}$.

Considering that the variable grip strength was obtained only in the second interview, we carried out a cross-sectional data analysis. The measure of association used was the odds ratio (OR) for the bivariate analysis, and the binary logistic regression was carried out by a conceptual hierarchical model, using the backward stepwise method (Likelihood Ratio).

Variables with $\mathrm{p}<0.20$ in the bivariate analysis were selected to compose the hierarchical conceptual model. The model was defined in three levels: distal (demographic and socioeconomic characteristics), intermediate (characteristics related to life habits and

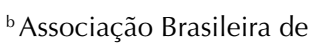
Empresas de Pesquisa. Critério de Classificação Econômica Brasil. São Paulo; 2009 [cited 2011 Oct 10]. Available from: http://www.abep.org/Servicos/ Download.aspx?id=04

cWorld Health Organization. The anatomical therapeutic chemical classification system with defined daily doses (ATC/DDD). [cited 2012 Dec 05]. Available from: https:// www.yumpu.com/en/document/ view/4414280/guidelines-foratc-classification-and-dddassignment-whocc health conditions), and proximal (characteristics related to functional capacity), considering the temporal precedence of the factors for a fall (Figure). We decided to keep the economic class for adjustment in the distal level in the modeling, regardless of the statistical outcome.

The variables of the distal level were adjusted by those of the same level. The variables of the intermediate level were adjusted by the variables with $\mathrm{p}<0.10$ in the previous adjustment and by variables of the same level, and the variables of the proximal level were adjusted by the variables with $\mathrm{p}<0.10$ in the previous adjustment and by variables of the same level. We excluded from the multiple analysis individuals with any field that was not informed or encoded as ignored. The level of significance adopted for the analyses was 5\% (Wald test). For all variables, we established a reference category $(\mathrm{OR}=1)$, considered as the lowest risk for a fall.

The statistical analyses were performed with the aid of the program SPSS 19.0. 
This study was approved by the Research Ethics Committee of the Universidade Estadual de Londrina for the first (CAAE 0192.0.268.000-10) and second research (CAAE 0021.0.268.000-11). The participants signed the informed consent.

\section{RESULTS}

The average age of the 404 individuals assessed in the two studies was 65.5 years (standard deviation of 7.1 years). More than half (59.4\%) of the interviewees were female, $66.6 \%$ reported being white or yellow, $67.1 \%$ were married or had a stable union, and $54.2 \%$ were considered as economic class C. Average education was 4.4 years (standard deviation of 4.2 years). Of the total, $22.8 \%$ regularly practiced some physical activity and $14.6 \%$ were smokers. The continued use of at least one psychotropic drug was mentioned by $19.6 \%$ of the interviewees. The sleep quality of $39.4 \%$ of the population was considered poor, $20.0 \%$ reported medical diagnosis of depression, $16.1 \%$ of diabetes mellitus, $12.1 \%$ of chronic obstructive pulmonary disease, $6.7 \%$ of neoplasm, $40.1 \%$ of hypertension, and $4.5 \%$ of heart failure.

Just over one third (36.6\%) of the interviewees mentioned difficulty going up or down the stairs, $12.4 \%$ had hearing impairment, and $10.9 \%$ had visual impairment. Most of the population under study was considered as independent to carry out activities (98.5\%) and instrumental activities (85.9\%) of daily living.

Fall from the first interview was mentioned by $24.3 \%$ of the individuals (95\%CI 20.1-28.5) and, of this number, $64.3 \%$ (95\%CI 54.8-73.8) reported a single fall. We observed an increase of falls according to an increase in age: 15.6\% (95\%CI 8.1-23.1) for individuals aged between 55 and 59 years, $19.0 \%$ (95\%CI 11.9-26.1) for those aged between 60 and 64 years, and 31.3\% (95\%CI 24.8-37.8) for those aged 65 years or more.

In the bivariate analysis, we observed higher chances of falls $(\mathrm{p}<0.05)$ among females, aged 65 years or more (Table 1), with poor sleep quality, diagnosis of depression (Table 2 ), difficulty

Table 1. Risk factors (not adjusted) for a fall, related to the demographic and socioeconomic characteristics. Cambé, State of Paraná, Southern Brazil, 2011 to 2012. ( $N=404)$

\begin{tabular}{|c|c|c|c|c|c|c|}
\hline \multirow{2}{*}{ Variable } & \multirow{2}{*}{$\begin{array}{c}\text { Total } \\
\mathrm{N} \\
\end{array}$} & \multicolumn{2}{|c|}{ Fall (yes) } & \multirow{2}{*}{ Not adjusted OR } & \multirow{2}{*}{$95 \% \mathrm{Cl}$} & \multirow{2}{*}{$\mathbf{p}^{\mathbf{a}}$} \\
\hline & & $\mathbf{n}$ & $\%$ & & & \\
\hline \multicolumn{7}{|l|}{ Gender } \\
\hline Male & 164 & 24 & 14.6 & 1 & - & \\
\hline Female & 240 & 74 & 30.8 & 2.60 & $1.56-4.34$ & $<0.001$ \\
\hline \multicolumn{7}{|l|}{ Age (years) } \\
\hline 55 to 64 & 206 & 36 & 17.5 & 1 & - & \\
\hline$\geq 65$ & 198 & 62 & 31.3 & 2.15 & $1.35-3.44$ & 0.001 \\
\hline \multicolumn{7}{|l|}{ Marital status } \\
\hline With partner & 271 & 63 & 23.2 & 1 & - & \\
\hline Without partner & 133 & 35 & 26,3 & 1.18 & $0.73-1.90$ & 0.449 \\
\hline \multicolumn{7}{|l|}{ Race } \\
\hline Black/Brown/Indigenous & 135 & 28 & 20.7 & 1 & - & \\
\hline White/Yellow & 269 & 70 & 26.0 & 1.34 & $0.82-2.21$ & 0.244 \\
\hline \multicolumn{7}{|c|}{ Education level (complete years) ${ }^{b}$} \\
\hline 0 to 3 & 88 & 22 & 25.0 & 1 & - & \\
\hline 4 to 7 & 136 & 26 & 19.1 & 0.71 & $0.37-1.35$ & 0.296 \\
\hline$\geq 8$ & 179 & 50 & 27.9 & 1.16 & $0.65-2.08$ & 0.612 \\
\hline \multicolumn{7}{|l|}{ Economy class $(\mathrm{ABEP})^{\mathrm{b}}$} \\
\hline $\mathrm{A} / \mathrm{B}$ & 119 & 26 & 21.8 & 1 & - & \\
\hline $\mathrm{C}$ & 219 & 54 & 24.7 & 1.17 & $0.69-1.99$ & 0.562 \\
\hline $\mathrm{D} / \mathrm{E}$ & 65 & 18 & 27.7 & 1.37 & $0.68-2.75$ & 0.375 \\
\hline
\end{tabular}

ABEP: Associação Brasileira de Empresas de Pesquisa (Brazilian Association of Research Companies).

${ }^{a}$ Wald Chi-square.

${ }^{\mathrm{b}}$ Information missing for one interview. 
going up or down the stairs, considered as dependents to carry out activities of daily living, and with low grip strength (Table 3).

The adjustment of the variables of the distal level, in the hierarchical analysis, showed that being female and aged $\geq 65$ years increase the chance of falls. At the intermediate level, poor sleep quality was the only statistically significant factor for a fall, regardless of the variables of that level and of the previous level. Only low muscle strength ( $\leq 25$ th percentile) was associated with a fall in the proximal level after adjusting for variables of the same level and of the previous levels (Table 4).

Table 2. Risk factors (not adjusted) for a fall, related to life habits and health conditions. Cambé, State of Paraná, Southern Brazil, 2011 to 2012. ( $\mathrm{N}=404)$

\begin{tabular}{|c|c|c|c|c|c|c|}
\hline \multirow{2}{*}{ Variable } & \multirow{2}{*}{$\begin{array}{c}\text { Total } \\
\mathrm{N}\end{array}$} & \multicolumn{2}{|c|}{ Fall (Yes) } & \multirow{2}{*}{ Not adjusted OR } & \multirow{2}{*}{$95 \% \mathrm{Cl}$} & \multirow{2}{*}{$\mathbf{p}^{\mathrm{a}}$} \\
\hline & & $\mathbf{n}$ & $\%$ & & & \\
\hline \multicolumn{7}{|c|}{ Practice of physical activity } \\
\hline Yes & 75 & 18 & 24.0 & 1 & - & \\
\hline No & 329 & 80 & 24.3 & 1.02 & $0.57-1.83$ & 0.954 \\
\hline \multicolumn{7}{|l|}{ Smoking } \\
\hline No & 345 & 84 & 24.3 & 1 & - & \\
\hline Yes & 59 & 14 & 23.7 & 0.97 & $0.51-1.85$ & 0.918 \\
\hline \multicolumn{7}{|c|}{ Use of psychotropic substances ${ }^{b}$} \\
\hline No & 271 & 70 & 25.8 & 1 & - & \\
\hline Yes & 132 & 28 & 21.2 & 0.77 & $0.47-1.27$ & 0.310 \\
\hline \multicolumn{7}{|c|}{ Quality of sleep ${ }^{c}$} \\
\hline Good & 224 & 44 & 19.6 & 1 & - & \\
\hline Poor & 157 & 49 & 31.2 & 1.86 & $1.16-2.98$ & 0.011 \\
\hline \multicolumn{7}{|c|}{ Heart failure ${ }^{d}$} \\
\hline No & 386 & 96 & 23.8 & 1 & - & \\
\hline Yes & 18 & 6 & 33.3 & 1.60 & $0.58-4.38$ & 0.362 \\
\hline \multicolumn{7}{|c|}{ Diabetes mellitus ${ }^{d}$} \\
\hline No & 339 & 83 & 24.5 & 1 & - & \\
\hline Yes & 65 & 15 & 23.1 & 0.93 & $0.49-1.73$ & 0.809 \\
\hline \multicolumn{7}{|c|}{ Depression $^{\mathrm{d}}$} \\
\hline No & 323 & 69 & 21.4 & 1 & - & \\
\hline Yes & 81 & 29 & 35.8 & 2.05 & $1.21-3.48$ & 0.007 \\
\hline \multicolumn{7}{|l|}{$\mathrm{COPD}^{\mathrm{d}}$} \\
\hline No & 355 & 87 & 24.5 & 1 & - & \\
\hline Yes & 49 & 11 & 22.4 & 0.89 & $0.44-1.82$ & 0.753 \\
\hline \multicolumn{7}{|c|}{ Neoplasm ${ }^{d}$} \\
\hline No & 377 & 88 & 23.3 & 1 & - & \\
\hline Yes & 27 & 10 & 37.0 & 1.93 & $0.85-4.37$ & 0.114 \\
\hline \multicolumn{7}{|c|}{ Hypertension } \\
\hline No & 242 & 54 & 22.3 & 1 & - & \\
\hline Yes & 162 & 44 & 27.2 & 1.30 & $0.82-2.06$ & 0.265 \\
\hline \multicolumn{7}{|l|}{ Obesity $^{\mathrm{e}}$} \\
\hline No & 262 & 58 & 22.1 & 1 & - & \\
\hline Yes & 133 & 38 & 28.6 & 1.41 & $0.87-2.27$ & 0.159 \\
\hline $\begin{array}{l}\text { COPD: Chr } \\
\text { a Wald Chi- } \\
\text { b Informatic } \\
{ }^{c} \text { Informatic } \\
\text { d Medical } \\
\text { e Informatic }\end{array}$ & $\begin{array}{l}\text { disease } \\
\text { ee. } \\
\text { nterviev } \\
\text { erviewe } \\
\text { vees. }\end{array}$ & & & & & \\
\hline
\end{tabular}


Table 3. Risk factors (not adjusted) for a fall, related to functional capacity. Cambé, State of Paraná, Southern Brazil, 2011 to 2012. $(\mathrm{N}=404)$

\begin{tabular}{|c|c|c|c|c|c|c|}
\hline \multirow{2}{*}{ Variable } & \multirow{2}{*}{$\begin{array}{c}\text { Total } \\
\mathrm{N}\end{array}$} & \multicolumn{2}{|c|}{ Fall (Yes) } & \multirow{2}{*}{ Not adjusted OR } & \multirow{2}{*}{$95 \% \mathrm{Cl}$} & \multirow{2}{*}{$\mathbf{p}^{*}$} \\
\hline & & $\mathbf{n}$ & $\%$ & & & \\
\hline \multicolumn{7}{|l|}{ Visual impairment } \\
\hline No & 360 & 89 & 24.7 & 1 & - & \\
\hline Yes & 44 & 9 & 20.5 & 0.78 & $0.36-1.69$ & 0.534 \\
\hline \multicolumn{7}{|l|}{ Hearing impairment } \\
\hline No & 354 & 81 & 22.9 & 1 & - & \\
\hline Yes & 50 & 17 & 34.0 & 1.74 & $0.92-3.28$ & 0.089 \\
\hline \multicolumn{7}{|c|}{ Difficulty of going up/down the stairs } \\
\hline No & 256 & 46 & 18.0 & 1 & - & \\
\hline Yes & 148 & 52 & 35.1 & 2.47 & $1.55-3.94$ & $<0.001$ \\
\hline \multicolumn{7}{|l|}{ ADL } \\
\hline Independent & 382 & 88 & 23.0 & 1 & - & \\
\hline Dependent & 22 & 10 & 45.5 & 2.78 & $1.16-6.66$ & 0.021 \\
\hline \multicolumn{7}{|l|}{ IADL } \\
\hline Independent & 274 & 59 & 21.5 & 1 & - & \\
\hline Dependent & 130 & 39 & 30.0 & 1.56 & $0.97-2.51$ & 0.065 \\
\hline \multicolumn{7}{|l|}{ Grip strength } \\
\hline$>25$ th percentile & 287 & 53 & 18.5 & 1 & - & \\
\hline$\leq 25$ th percentile & 117 & 45 & 38.5 & 2.76 & $1.71-4.45$ & $<0.001$ \\
\hline
\end{tabular}

ADL: Activities of daily living; IADL: Instrumental activities of daily living

* Wald Chi-square.

Table 4. Hierarchical logistic regression of the factors associated with a fall in persons aged 55 years or more. Cambé, State of Paraná, Southern Brazil, 2011 to 2012. ( $\mathrm{N}=372)$

\begin{tabular}{|c|c|c|c|c|c|c|}
\hline \multirow{2}{*}{ Variable } & \multirow{2}{*}{$\frac{\text { Total }}{\mathrm{N}}$} & \multicolumn{2}{|c|}{ Fall (yes) } & \multirow{2}{*}{ Adjusted OR } & \multirow{2}{*}{$95 \% \mathrm{Cl}$} & \multirow{2}{*}{$\mathbf{p}^{\mathbf{a}}$} \\
\hline & & $n$ & $\%$ & & & \\
\hline \multicolumn{7}{|l|}{ Distal levela } \\
\hline \multicolumn{7}{|l|}{ Gender } \\
\hline Male & 153 & 21 & 13.7 & 1 & - & \\
\hline Female & 219 & 70 & 32.0 & 3.10 & $1.79-5.38$ & $<0.001$ \\
\hline \multicolumn{7}{|l|}{ Age (years) } \\
\hline 55 to 64 & 191 & 33 & 17.3 & 1 & - & \\
\hline$\geq 65$ & 181 & 58 & 32.0 & 2.39 & $1.45-3.95$ & 0.001 \\
\hline \multicolumn{7}{|l|}{ Intermediate level ${ }^{\mathrm{b}}$} \\
\hline \multicolumn{7}{|l|}{ Quality of sleep } \\
\hline Good & 218 & 42 & 19.3 & 1 & - & \\
\hline Poor & 154 & 49 & 31.8 & 1.78 & $1.08-2.93$ & 0.023 \\
\hline \multicolumn{7}{|l|}{ Proximal level ${ }^{c}$} \\
\hline \multicolumn{7}{|l|}{ Muscle strength } \\
\hline$>25$ th percentile & 271 & 51 & 18.8 & 1 & - & \\
\hline$\leq 25$ th percentile & 101 & 40 & 39.6 & 2.31 & $1.34-3.97$ & 0.003 \\
\hline
\end{tabular}

a Level adjusted for economic class, age, and gender.

${ }^{\mathrm{b}}$ Level adjusted for age, gender, sleep quality, depression, neoplasm, and body mass index.

c Level adjusted for age, gender, sleep quality, depression, difficulty of going up/down the stairs, hearing impairment, activities of daily living, instrumental activities of daily living, and grip strength.

\section{DISCUSSION}

The report of a fall in the population studied (24.3\%) was lower when compared to studies carried out with an older population, although the associated factors have been similar. In a cohort of 1,415 individuals aged 65 years or more, living in the city of São Paulo, State of São Paulo, 30.9\% reported fall on the year previous to the interview ${ }^{16}$. In other population-based studies in Brazil, the prevalence of falls over the past 12 months among the elderly aged 60 years or more was $27.6 \%$ in urban areas of one hundred municipalities of twenty-three States ${ }^{22}$, 
27.1\% in Montes Claros, State of Minas Gerais ${ }^{17}$, and $30.3 \%$ in a municipality in the State of Rio de Janeiro ${ }^{15}$. The lower frequency of falls identified in this research may be related to the composition of the sample, which includes adults aged from 55 years, and the predominance of individuals who are independent to carry out activities and instrumental activities of daily living.

This study has identified a significant association between falls and being female and of old age, regardless of economic class. Authors highlight the more frequent execution of domestic activities ${ }^{16}$ and greater loss of lean mass and muscle strength ${ }^{14}$ as possible causes of the higher incidence of falls among women. The advance of age leads to structural and functional changes that can reduce the ability to balance quickly and effectively, compromise the performance of motor skills, muscle strength, gait, and postural stability, and make an individual vulnerable to falls ${ }^{1}$.

Poor sleep quality has also been identified as a risk factor for falls even after adjusting for variables such as gender, age, and depression. This result was similar to that presented by Stone et al..$^{25}$ in a study in the United States with 3,101 individuals, in which poor sleep quality assessed using the PSQI has been significantly associated with higher chance of falls.

After adjustment, the variable depression has not been associated with falls in this study, but depression can be related to a reduction in the speed of gait and loss of muscle strength, characteristics that are related to the occurrence of a fall ${ }^{18}$. According to Ricci et al. ${ }^{19}$, depressive symptoms deserve appropriate treatment and care, because of their debilitating consequences and association with falls, as they may have a devastating effect on the quality of life of the individual.

Low grip strength has also proved to be associated with falls, regardless of other variables such as sleep quality, depression, and difficulty going up/down the stairs. Visser et al. ${ }^{27}$ have identified higher risk of functional decline, falls, and mortality in older individuals with low muscle strength. The loss of muscle strength is considered an important indicator of frailty and is directly related with the increase in the number of falls, difficulty in going up or down the stairs, loss of agility, and fractures ${ }^{3}$.

Characteristics recognized as risk factors for falls, such as visual impairment, presence of other chronic diseases, and use of drugs ${ }^{2}$, have shown no association with this outcome in this research. Falls in the elderly are a multicausal event with numerous factors that act together and interact with each other'. This contributes to make it less likely that a given variable will stay associated with the event analyzed in the multiple model, in which other important factors were included.

This study has limitations. As this is a study developed in two moments, there were losses of individuals between the first and the second home interviews, although we have searched for information with neighbors and community health agents (ACS) and also from phone contacts, as strategies to minimize the losses. Another limitation is related to the fact that the fall was self-reported, a condition subject to the recall bias of the interviewee. Important characteristics for understanding the outcome, as environmental obstacles, wet surfaces, inadequate footwear ${ }^{2}$, among others, were not included in the analysis. Some health conditions, although included, did not make part of the multiple model, even though there was theoretical justification (such as the use of psychotropic drugs, hypertension, and diabetes), because of the low sample size. Some diseases, such as osteoarthritis, were not analyzed. The variable related to obesity grouped persons with low weight to normal weight or on the overweight range in the same category, which may have reduced the frequency of falls in this group and the difference in relation to persons with obesity. Furthermore, as the data was analyzed cross-sectionally, we cannot rule out the possibility of reverse causality, particularly in the relationship between falls and muscle strength. Falls can cause fractures - in a large study conducted in Brazil ${ }^{22}, 11.0 \%$ of the elderly who suffered falls reported fractures - and, consequently, reduce muscle strength.

This research used data from a population-based study, which has allowed us to identify factors associated with falls in a population aged 55 years or more, with lower risk for this outcome 
than that observed in the elderly. These factors can be indicators of early loss of functional independence in this population. In addition, a hierarchical conceptual model was used for the study of factors associated with falls, and we have included demographic and socioeconomic characteristics related to lifestyle, presence of chronic diseases, and functional capacity.

The results found in this research are important to guide the actions of professionals who work in Family Health Units and Centers of Support to Family Health, as well as public policies, such as: encouragement of the practice of physical activity to strengthen muscles ${ }^{6}$, expanding of outdoor academies facilities, promotion of continuing education on environmental hazards and risk attitudes in the context of aging ${ }^{12}$, and identification of individuals at risk for falls, such as those with poor sleep quality, for proper care.

In summary, the frequency of falls identified in this research was lower than that of studies carried out only with the elderly population. In addition to being female and of old age, modifiable factors, such as poor sleep quality and low muscle strength, stood out as risk for falls. The identification of this profile may collaborate in directing health actions focused on the prevention of falls.

\section{REFERENCES}

1. Abreu S, Caldas C. Velocidade de marcha, equilíbrio e idade: um estudo correlacional entre idosas praticantes e idosas não praticantes de um programa de exercícios terapêuticos. Rev Bras Fisioter. 2008;12(4):324-30. https://doi.org/10.1590/S1413-35552008000400012

2. Ambrose AF, Paul G, Hausdorff JM. Risk factors for falls among older adults: a review of the literature. Maturitas. 2013;75(1):51-61. https://doi.org/10.1016/j.maturitas.2013.02.009

3. Bohannon RW, Bear-Lehman J, Desrosiers J, Massy-Westropp N, Mathiowetz V. Average grip strength: a meta-analysis of data obtained with a Jamar dynamometer from individuals 75 years or more of age. J Geriatr Phys Ther. 2007;30(1):28-30. https://doi.org/10.1519/00139143-200704000-00006

4. Buysse DJ, Reynolds CF, Monk TH, Berman SR, Kupfer DJ. The Pittsburgh Sleep Quality Index: a new instrument for psychiatric practice and research. Psychiatry Res. 1989;28(2):193-213. https://doi.org/10.1016/0165-1781(89)90047-4

5. Deandrea S, Lucenteforte E, Bravi F, Foschi R, La Vecchia C, Negri E. Risk factors for falls in community-dwelling older people: a systematic review and meta-analysis. Epidemiology. 2010;21(5):658-68. https://doi.org/10.1097/EDE.0b013e3181e89905

6. El-Khoury F, Cassou B, Charles MA, Dargent-Molina P. The effect of fall prevention exercise programmes on fall induced injuries in community dwelling older adults: systematic review and meta-analysis of randomised controlled trials. BMJ. 2013;347:f6234. https://doi.org/10.1136/bmj.f6234

7. Fess EE. Grip strength. In: Casanova JS, editor. Clinical assessment recommendations. 2.ed. Chicago: American Society of Hand Therapists; 1992. p.41-5.

8. Haskell WL, Lee IM, Pate RR, Powell KE, Blair SN, Franklin BA, et al. Physical activity and public health: updated recommendation for adults from the American College of Sports Medicine and the American Heart Association. Med Sci Sports Exerc. 2007;39(8):1423-34. https://doi.org/10.1249/mss.0b013e3180616b27

9. Inouye SK, Studenski S, Tinetti ME, Kuchel GA. Geriatric syndromes: clinical, research, and policy implications of a core geriatric concept. J Am Geriatr Soc. 2007;55(5):780-91. https://doi.org/10.1111/j.1532-5415.2007.01156.x

10. Katz S, Ford AB, Moskowitz RW, Jackson BA, Jaffe MW. Studies of Illness in the aged: The Index of ADL: a standardized measure of biological and psychosocial function. JAMA. 1963;185(12):914-9. https://doi.org/10.1001/jama.1963.03060120024016

11. Katz S, Downs TD, Cash HR, Grotz RC. Progress in development of the index of ADL. Gerontologist. 1970;10(1):20-30.

12. Kenny R, Rubenstein LZ, Tinetti ME, Brewer K, Cameron KA, Capezuti EA, et al. Summary of the updated American Geriatrics Society/British Geriatrics Society clinical practice guideline for prevention of falls in older persons. J Am Geriatr Soc. 2011;59(1):148-57. https://doi.org/10.1111/j.1532-5415.2010.03234.x 
13. Lawton MP, Brody EM. Assessment of older people: self-maintaining and instrumental activities of daily living. Gerontologist. 1969;9(3):179-86. https://doi.org/10.1093/geront/9.3_Part_1.179

14. Lebrão ML, Laurenti R. Saúde, bem-estar e envelhecimento: o estudo SABE no município de São Paulo. Rev Bras Epidemiol. 2005;8(2):127-41. https://doi.org/10.1590/S1415-790X2005000200005

15. Motta LB, Aguiar AC, Coutinho ESF, Huf G. Prevalência e fatores associados a quedas em idosos em um município do Rio de Janeiro. Rev Bras Geriatr Gerontol. 2010;13(1):83-91. https://doi.org/10.1590/S1809-98232010000100009

16. Perracini MR, Ramos LR. Fatores associados a quedas em uma coorte de idosos residentes na comunidade. Rev Saude Publica. 2002;36(6):709-16. https://doi.org/10.1590/S0034-89102002000700008

17. Ramos GCF, Carneiro JA, Barbosa ATF, Mendonça JMG, Caldeira AP. Prevalência de sintomas depressivos e fatores associados em idosos no norte de Minas Gerais: um estudo de base populacional. J Bras Psiquiatr. 2015;64(2):122-31. https://doi.org/10.1590/0047-2085000000067

18. Rao SS. Prevention of falls in older patients. Am Fam Physician. 2005;72(1):81-8.

19. Ricci NA, Gonçalves DFF, Coimbra IB, Coimbra AMV. Fatores associados ao histórico de quedas de idosos assistidos pelo programa de Saúde da Família. Saude Soc. 2010;19(4):898-909. https://doi.org/10.1590/S0104-12902010000400016

20. Silva RB, Eslick GD, Duque G. Exercise for falls and fracture prevention in long term care facilities: a systematic review and meta-analysis. J Am Med Dir Assoc. 2013;14(9):685-9.e2. https://doi.org/10.1016/j.jamda.2013.05.015

21. Silveira EA, Kac G, Barbosa LS. Prevalência e fatores associados à obesidade em idosos residentes em Pelotas, Rio Grande do Sul, Brasil: classificação da obesidade segundo dois pontos de corte do índice de massa corporal. Cad Saude Publica. 2009;25(7):1569-77. https://doi.org/10.1590/S0102-311X2009000700015

22. Siqueira FV, Facchini LA, Silveira DS, Piccini RX, Tomasi E, Thumé E, et al. Prevalence of falls in elderly in Brazil: a countrywide analysis. Cad Saude Publica. 2011;27(9):1819-26. https://doi.org/10.1590/S0102-311X2011000900015

23. Souza RKT, Bortoletto MSS, Loch MR. Prevalência de fatores de risco cardiovascular em pessoas com 40 anos ou mais de idade, em Cambé, Paraná (2011): estudo de base populacional. Epidemiol Serv Saude. 2013;22(3):435-44. https://doi.org/10.5123/S1679-49742013000300008

24. Stone C, Lawlor PG, Nolan B, Kenny RA. A prospective study of the incidence of falls in patients with advanced cancer. J Pain Symptom Manage. 2011;42(4):535-40. https://doi.org/10.1016/j.jpainsymman.2011.01.006

25. Stone KL, Blackwell TL, Ancoli-Israel S, Cauley JA, Redline S, Marshall LM, et al. Sleep disturbances and risk of falls in older community-dwelling men: the outcomes of Sleep Disorders in Older Men (MrOS Sleep) Study. J Am Geriatr Soc. 2014;62(2):299-305. https://doi.org/10.1111/jgs.12649.

26. Tas U, Verhagen AP, Bierma-Zeinstra SM, Hofman A, Odding E, Pols HA, et al. Incidence and risk factors of disability in the elderly: the Rotterdam Study. Prev Med. 2007;44(3):272-8 https://doi.org/10.1016/j.ypmed.2006.11.007

27. Visser M, Schaap LA. Consequences of sarcopenia. Clin Geriatr Med. 2011;27(3):387-99. https://doi.org/10.1016/j.cger.2011.03.006

28. Yu PL, Qin ZH, Shi J, Zhang J, Xin MZ, Wu ZL, et al. Prevalence and related factors of falls among the elderly in an urban community of Beijing. Biomed Environ Sci. 2009;22(3):179-87. https://doi.org/10.1016/S0895-3988(09)60043-X

Funding: National Council for Scientific and Technological Development (CNPq - Process 150173/2013-0 junior post-doc [PDJ]).

Authors' Contribution: Planning of the study, data analysis, preparation, and critical review of the study: SCFP, SMA, MASC, RMD. Data analysis and critical review of the study: HGS, MSGD, AEM.

Conflict of Interest: The authors declare no conflict of interest. 